\title{
Drug utilization study in schizophrenia patients in outpatient department of psychiatry: an observational prospective study
}

\author{
Nitin Sukadev Hivale, Madhuri D. Kulkarni*, Siddharth S. Athawale
}

Department of Pharmacology, Government Medical College, Aurangabad, Maharashtra, India

Received: 26 December 2019

Accepted: 11 February 2020

*Correspondence:

Dr. Madhuri D. Kulkarni,

Email: mkulkarni48@gmail.com

Copyright: (C) the author(s), publisher and licensee Medip Academy. This is an open-access article distributed under the terms of the Creative Commons Attribution Non-Commercial License, which permits unrestricted non-commercial use, distribution, and reproduction in any medium, provided the original work is properly cited.

\begin{abstract}
Background: A mental disorder or psychiatry disorder is a behavioural or mental pattern that causes significant distress or impairment of personal functioning. Schizophrenia is one of the most common psychiatric disorders. Aim of the study is to study drug utilization pattern in schizophrenia patients in outpatient department of psychiatry.

Methods: A prospective and observational study was conducted in psychiatry outpatient department between May 2018 to October 2018 at Government Medical College and Hospital Aurangabad. Approval from ethics committee was taken. Data collected was of age, sex, final diagnosis, drugs prescribed to patients from case report form. The data obtained was then analyzed in Microsoft excel.

Results: Total prescriptions of 129 patients were analyzed. Out of 129 patients 99 (76.74\%) were male, while 30 $(23.26 \%)$ were female. The mean age of the patients admitted in Psychiatry OPD was $36.71 \pm 11.76$ years. Number of drugs prescribed per patient being 3.40 \pm 1.12 (mean \pm SD). The most common drugs used were olanzapine $(66.6 \%)$, trihexyphenidyl (51.9\%), lorazepam $(44.9 \%)$, risperidone $(39.5 \%)$, trifluoperazine $(27.9 \%)$.

Conclusions: Our study shows that atypical antipsychotics were the most common drugs prescribed in patients. Olanzapine was the most common medication used followed by risperidone. Our prospective study is carried out to get a more comprehensive data so that we can improve the drug utilization in our hospital.
\end{abstract}

Keywords: Drugs utilization study, Schizophrenia, Antipsychotics, Olanzapine

\section{INTRODUCTION}

WHO defined drug utilization research in 1977 as "the marketing, distribution, prescription, and use of drugs in a society, with special emphasis on the resulting medical, social and economic consequences". The main aim of drug utilization study is to facilitate rational use of medicines. There is increased incidence of treatment failure, adverse effect of drugs, non-compliant of patient and economic burden on the patient and the community as a whole due to irrational prescribing. ${ }^{1}$

A mental disorder or psychiatry disorder is a behavioural or mental pattern that causes significant distress or impairment of personal functioning. Sign and symptoms in psychiatry patient may be persistent, relapsing and remitting or occur as a single episode. ${ }^{2}$

Schizophrenia is one of the most common psychiatric disorders, estimated to affect $0.4 \%$ to $1.4 \%$ of the population. It has a mean annual incidence of 11-16 per $100,000 .^{3}$ It affects men and women equally; however, there is an earlier onset in males. ${ }^{4}$ Schizophrenia is considered the prototypic disorder for understanding the phenomenology of psychosis and the impact of antipsychotic treatment, but patients with schizophrenia exhibit features that extend beyond those seen in other psychotic illnesses. Hallucinations, delusions, 
disorganized speech, and disorganized or agitated behaviour comprise the types of psychotic symptoms found individually, or rarely together, in all psychotic disorders, and are typically responsive to pharmacotherapy. ${ }^{5}$

Mental disorder patient has huge impact on their routine lifestyle. Therefore, it is responsibility of general physicians and specialists have to deal with the challenge of treating the symptoms and ensuring a decent quality of life for their patients. Schizophrenia requires prolonged treatment, even when symptoms have subsided. Treatment with medications and psychosocial therapy can help manage the condition. People with schizophrenia often lack awareness that their difficulties is due to a mental disorder that requires medical attention. Therefore, it often falls to family or friends to get them help. Treatment of such patients at an early stage may prevent loss of morbidity, mortality and productivity. ${ }^{6}$

Although there are many studies to evaluate drug utilization pattern on mental disorder, this study has been specifically designed to show how drug has been utilized for Schizophrenia patient of either sex, age, previous any history of patient and guidelines used on outpatient department (OPD) basis in psychiatry department in tertiary care teaching hospital in India.

\section{METHODS}

A prospective and observational study was conducted in psychiatry OPD between May 2018 to October 2018 at Government Medical College and Hospital Aurangabad.

\section{Study criteria}

\section{Inclusion criteria}

Schizophrenia patient coming to psychiatry OPD in tertiary care teaching hospital who or whose relatives are willing to give informed consent. Schizophrenia patient of both sex and patient having age above 18 years and schizophrenia patient prescribed at least one psychotropic drug included.

\section{Exclusion criteria}

Patient or relatives not willing to give informed consent. Incomplete data entry case records were excluded from the study.

Approval from ethics committee was taken. Informed consent was taken from the patient's fulfilling inclusion criteria. Data collected was of age, sex, final diagnosis, drugs prescribed to patients from case papers. The data obtained was then analyzed in Microsoft excel. Qualitative data are expressed in frequency and percentage while quantitative data are expressed with mean \pm standard deviation (SD).

\section{RESULTS}

The prospective observational study was carried out at tertiary care teaching hospital in psychiatry outpatient department.

Total prescriptions of 129 patients were analyzed from the outpatient department of psychiatry. Detailed information about baseline demographic characteristics and treatment received by the patient was studied.

Out of 129 patients $99(76.74 \%)$ were male, while 30 $(23.26 \%)$ were female (Table 1) The mean age of the patients admitted in psychiatry OPD was $36.71 \pm 11.76$ years (Table 1).

Table 1: Sex distribution $(\mathrm{n}=129)$.

\begin{tabular}{|ll|}
\hline Demographic & Frequency $(\%)$ \\
\hline Male & $99(76.74)$ \\
\hline Female & $30(23.26)$ \\
\hline Age (mean \pm SD) $(\mathbf{y r s})$ & $36.71 \pm 11.76$ \\
\hline
\end{tabular}

Table 2: Age distribution $(n=129)$.

\begin{tabular}{|lll|}
\hline Age distribution (in yrs) & $\mathbf{N}$ & $\%$ \\
\hline $\mathbf{1 8 - 2 5}$ & 24 & 18.60 \\
\hline $\mathbf{2 6 - 3 5}$ & 41 & 31.78 \\
\hline $\mathbf{3 6 - 4 5}$ & 38 & 29.46 \\
\hline $\mathbf{4 6 - 5 5}$ & 17 & 13.18 \\
\hline $\mathbf{5 6 - 6 5}$ & 6 & 4.65 \\
\hline $\mathbf{6 6 - 7 5}$ & 3 & 2.33 \\
\hline Total & 129 & 100 \\
\hline
\end{tabular}

\section{Drug utilization pattern}

A total of 129 patients from psychiatry OPD received 439 drugs, number of drugs prescribed per patient being $3.40 \pm 1.12$ (mean \pm standard deviation) (Table 3). The total number of drugs prescribed per prescription in psychiatry OPD are most commonly between 1-2 (23.26\%) drugs, between 3-4 were $60.47 \%$ and between 5-6 were $16.28 \%$ (Table 3).

Table 3: Drugs used per prescription $(n=129)$.

\begin{tabular}{|lll|}
\hline $\begin{array}{l}\text { Drugs per } \\
\text { prescriptions }\end{array}$ & $\begin{array}{l}\text { Total no of } \\
\text { prescriptions }\end{array}$ & $\%$ \\
\hline $\mathbf{1 - 2}$ & 30 & 23.26 \\
\hline $\mathbf{3 - 4}$ & 78 & 60.47 \\
\hline $\mathbf{5 - 6}$ & 21 & 16.28 \\
\hline Mean $\mathbf{S D}$ & $3.40 \pm 1.12$ & \\
\hline
\end{tabular}

The most common drugs used were olanzapine (66.6\%), trihexyphenidyl $(51.9 \%)$, lorazepam $(44.9 \%)$, risperidone $(39.5 \%)$, trifluoperazine $(27.9 \%)$, sodium valproate (20.1\%), clonazepam (15.5\%), clozapine (12.4\%), sertraline $(6.9 \%)$, quetiapine $(6.2 \%)$ (Table 4$)$. 
Table 4: Various drugs prescribed.

\begin{tabular}{|c|c|c|c|c|}
\hline S. no. & Drugs & No. of prescriptions & Percentage (\%) & ATC code \\
\hline 1 & Tablet olanzapine & 86 & 66.6 & N05AH03 \\
\hline 2 & Tablet trihexyphenidyl & 67 & 51.9 & N04AA01 \\
\hline 3 & Tablet lorazepam & 58 & 44.9 & N05BA06 \\
\hline 4 & Tablet risperidone & 51 & 39.5 & N05AX08 \\
\hline 5 & Tablet trifluoperazine and trihexyphenidyl & 36 & 27.9 & N05AB06 \\
\hline 6 & Tablet sodium valproate & 26 & 20.1 & N03AG01 \\
\hline 7 & Tablet clonazepam & 20 & 15.5 & N03AE01 \\
\hline 8 & Tablet clozapine & 16 & 12.4 & N05AH02 \\
\hline 9 & Tablet sertraline & 9 & 6.9 & N06AB06 \\
\hline 10 & Tablet quetiapine & 8 & 6.2 & N05AH04 \\
\hline 11 & Tablet carbamazepine & 8 & 6.2 & N03AF01 \\
\hline 12 & Tablet multivitamins/fsfa & 7 & 5.4 & A11AA01 \\
\hline 13 & Tablet divalproex & 6 & 4.6 & N03AG01 \\
\hline 14 & Tablet escitalopram & 6 & 4.6 & N06AB10 \\
\hline 15 & Tablet lithium carbonate & 5 & 3.8 & N05AN01 \\
\hline 16 & Tablet amisulpiride & 5 & 3.8 & N05AL05 \\
\hline 17 & Tablet haloperidol & 4 & 3.1 & N05AD01 \\
\hline 18 & Tablet promethazine & 4 & 3.1 & R06AD02 \\
\hline 19 & $\begin{array}{l}\text { Tablet trifluoperazine, chlorpromazine and } \\
\text { benzhexol }\end{array}$ & 4 & 3.1 & N05AB06 \\
\hline 20 & Tablet trifluoperazine & 3 & 2.3 & N05AB06 \\
\hline 21 & Tablet amitriptyline & 3 & 2.3 & N06AA09 \\
\hline 22 & Tablet fluoxetine & 2 & 1.5 & N06AB03 \\
\hline 23 & Tablet aripiprazole & 2 & 1.5 & N05AX12 \\
\hline 24 & Tablet nitrazepam & 1 & 0.7 & $\mathrm{~N} 05 \mathrm{CD} 02$ \\
\hline 25 & Tablet phenytoin & 1 & 0.7 & N03AB02 \\
\hline 26 & Tablet ranitidine & 1 & 0.7 & A02BA02 \\
\hline
\end{tabular}

\section{DISCUSSION}

In the present study, the number of male patients were $76.74 \%$ while that of female were $23.26 \%$ (Table 1,) which is similar to the studies done by Paul et al, Rode et al but contrary to the studies done by Thakkar et al, Dutta et al, which shows that psychiatric illness is more common in females respectively. ${ }^{5,7-9}$

In present study maximum patients belongs to middle socioeconomic group, 18-45 years of age which is comparable to study by Dutta et al (Table 2). ${ }^{9}$

The average number of psychotropic drugs per prescription was $3.40 \pm 1.12$, which is comparable with the findings of other studies where it ranged from 2 to 4 drugs per prescription done by Rode et al, Lahon et al and Rittmannsberger et al. ${ }^{7,10,11}$ It is preferable to keep the number of drugs per prescription as low as possible since polypharmacy leads to increased risk of drug interactions, increased hospital cost and errors of prescribing. It was seen that the prescriptions with the generic name was much less than the brand names, which suggests popularity of brand names among the medical practitioners, which is in contrast to the WHO guidelines, where generic prescription is one of the indicators for rational prescribing. Generic drug prescribing also facilitates cheaper treatment for the patient.

The most common antipsychotic prescribed was olanzapine followed by risperidone; this was also found in a study carried done by Paul et al, Lahon et al and Ghosh et al. ${ }^{5,12,13}$

As per the National Health Services (NHS), a guideline regarding the use of antipsychotics as first line agents it says that the first generation (typical) and second generation (atypical) antipsychotics are equally efficacious but when no consensus is reached between their uses it is preferable to start the second generation antipsychotics. ${ }^{14}$ In this study also it was seen that the second generation antipsychotics were used more compared to first generation to treat Schizophrenia. This findings had also been suggested by other studies done by Dutta et al. ${ }^{15}$ There is an increase use of atypical antipsychotic agents like olanzapine (66.6\%), risperidone (39.5\%), quetiapine (6.2\%) similar to the studies done by Banerjee et al and Siddiqui et al (Table 4). ${ }^{16,17}$ Because they have provided a better control of symptoms and reduced the chances of adverse effects especially the extrapyramidal ones in contrast with typical antipsychotic drugs and also proved to be better in improving negative 
symptoms, cognitive dysfunction and also efficacious in antipsychotic resistant cases.

In this study the most common fixed dose combination used was typical antipsychotic (trifluoperazine) with an anticholinergic (trihexyphenidyl) $27.9 \%$ which is similar to study done by Thakkar et al and Siddqui et al. ${ }^{8,17}$ (Table 4). Prescription of anti-cholinergics with both typical and atypical antipsychotics is very common to prevent extra-pyramidal side-effects (EPS). The use of such FDCs can be considered as rational when used for maintenance therapy in patients who had earlier developed EPS because of antipsychotic alone.

In this study, the anxiolytics like benzodiazepines were the most commonly used psychotropic drugs followed by anti-depressants and anti-psychotics which is similar to study done by Rode et al and Grover et al. ${ }^{7,18}$ Lorazepam (44.9\%) being the most common followed by clonazepam $(15.5 \%)$, suggesting a trend toward the use of shorter acting BZD as continuous and prolonged use of longer acting BZDs has resulted in dependence and may have withdrawal symptoms when the dose of the drug is reduced or stopped. Guidelines for the rational use of BZDs recommend their use for short-term (maximum 4 weeks) or intermittent courses in minimum effective doses, to be prescribed only when symptoms are severe. ${ }^{19}$

In the present study antidepressants, selective serotonin reuptake inhibitors (SSRI) like sertraline (6.9\%), escitalopram (4.6\%) were the most commonly prescribed compared to tricyclic anti-depressants like amitriptyline $(2.3 \%)$ which is similar to study done by Rode et al. ${ }^{7}$ SSRI are generally free of sedative effects and safer at higher doses. Better tolerability, combined with their mild adverse effects, accounts for their popularity as most widely prescribed antidepressants. ${ }^{20}$

\section{Limitations}

Our study was carried out with a short duration of time and factors like drug overdose, adverse effect profile, that would affect the prescribing pattern of the antipsychotic medications were needed to be evaluated. Defined daily dose, and pharmacoeconomics were not studied which would have given more understanding.

\section{CONCLUSION}

Antipsychotics are one of the commonly used medications for schizophrenia and other psychiatric disorders. Our study shows that atypical antipsychotics were the most common drugs prescribed in patients. Olanzapine was the most common medication used followed by risperidone. As the percentage of generic drug prescribing is low, the issue of frequent use of brand names needs to be addressed. Our study is an attempt to look at scenario of drug usage in the hospital and further prospective studies can be carried out to get a more comprehensive data so that we can improve the drug utilization in our hospital.

\section{ACKNOWLEDGEMENTS}

Author and his team would like to thank to HOD and all staff members in department of Psychiatry, tertiary care teaching hospital, Government Medical college for their good support and co-operation during the study.

Funding: No funding sources

Conflict of interest: None declared

Ethical approval: The study was approved by the Institutional Ethics Committee

\section{REFERENCES}

1. World Health Organization International Working Group for Drug Statistics Methodology. Introduction to Drug Utilization Research. Available at: http://apps.who.int/medicinedocs/pdf/s4876e/s4876e. pdf. 2003;1-48. Accessed on 20 December 2019.

2. NIMH. Prevalence of Any Mental Illness (AMI). 2016;1-8. Available at: https://www.nimh.nih.gov/ health/statistics/mental-illness.shtml\#part_154785. Accessed on 20 December 2019.

3. Kuipers E, Kendall T, Antoniou J. Schizophrenia, the NICE Guidelines on 11 core interventions in the treatment and management of schizophrenia in adults in primary and secondary care. The British Psychological Society \& the Royal College of Psychiatrists; 2010.

4. Jablensky A. Epidemiology of schizophrenia: the global burden of disease and disability. Eur Arch Psychiatry Clin Neurosci. 2000;250(6):274-85.

5. Paul PK, Konwar M, Das S. To study the prescribing pattern of antipsychotic drugs in a tertiary care hospital of Assam. Int $\mathrm{J}$ Pharm Pharm Sci. 2014;6(4):435-7.

6. Shanafelt TD, Noseworthy JH. Executive Leadership and Physician Well-being: Nine Organizational Strategies to Promote Engagement and Reduce Burnout. Mayo Clin Proc. 2017;92(1):129-46.

7. Rode SB, Ajagallay RK, Salankar HV Sinha U. A study on drug prescribing pattern in psychiatry outpatient department from a tertiary care teaching hospital. Int J Basic Clin Pharmacol. 2014;3(3):517-22.

8. Thakkar KB, Jain MM, Billa G, Joshi A, Khobragade AA. A drug utilization study of psychotropic drugs prescribed in the psychiatry outpatient department of a tertiary care hospital. J Clin Diagn Res. 2013;7(12):2759-64.

9. Dutta S, Beg MA, Kaul V, Dutta S, Dhasmana DC. Psychotropic drug utilization study in psychiatric opd of a tertiary care teaching hospital in Dehradun, Uttarakhand. J Adv Res Biol Sci. 2013;5(4):386-91.

10. Lahon K, Shetty H, Paramel A, Sharma G. A retrospective drug utilization study of antidepressants 
in the psychiatric unit of a tertiary care hospital. J Clin Diagn Res. 2011;5(5):1069-75.

11. Rittmannsberger $\mathrm{H}$, Meise U, Schauflinger $\mathrm{K}$, Horvath E, Donat H, Hinterhuber H. Polypharmacy in psychiatric treatment. Patterns of psychotropic drug use in Austrian psychiatric clinics. Eur Psychiatry. 1999;14(1):33-40.

12. Lahon K, Shetty HM, Paramel A, Sharma G. Pharmacoepidemiological study of antipsychotics in the psychiatry unit of a tertiary care hospital: a retrospective descriptive analysis. Int $\mathrm{J} \mathrm{Ntr}$ Pharmacol Neurol Dis. 2012;2:135-41.

13. Ghosh S, Bhattacharya S, Dalai CK. Antipsychotic Prescribing Pattern In A Tertiary Care Hospital In Eastern India. J Drug Delivery Therapeu. 2013;3(4):38-42.

14. Berkshire health care NHS foundation trust Antipsychotic guidelines. Treatment of schizophrenia and psychosis. 2011: 1-67.

15. Dutta SB, Dhasmana DC, Bhardwaj R. Psychotropic drug utilization pattern among schizophrenics. Ind $\mathbf{J}$ Psychiatry. 2004;46(4):381-2.

16. Banerjee I, Roy B, Sathian B, Banerjee I, Chakraborty PK, Saha A. Socio demographic profile and utilization pattern of antipsychotic drugs among schizophrenic inpatients: a cross sectional study from western region of Nepal. BMC Psychiatry. 2013;13:96.

17. Siddiqui RA, Shende TR, Mahajan HM, Borkar A. Antipsychotic medication prescribing trends in a tertiary care hospital. Int $\mathrm{J}$ Basic Clin Pharmacol. 2016;5:1417-20.

18. Grover S, Kumar V, Avasthi A, Kulhara P. An audit of first prescription of new patients attending a psychiatry walk-in-clinic in north India. Indian $\mathbf{J}$ Pharmacol. 2012;44(3):319-325.

19. Ashton H. Guidelines for the rational use of benzodiazepines. When and what to use. Drugs. 1994;48(1):25-40.

20. Potter WZ, Hollester LE. Antidepression agents. In: Katzung BG, editor. Basic and Clinical Pharmacology. 10th Edition. Boston: McGraw-Hill; 2007: 475-88.

Cite this article as: Hivale NS, Kulkarni MD, Athawale SS. Drug utilization study in schizophrenia patients in outpatient department of psychiatry: an observational prospective study. Int J Basic Clin Pharmacol 2020;9:475-9. 